\section{In vitro antimicrobial activity of Salvadora persica extract on Helicobacter pylori strains isolated from duodenal ulcer biopsies}

\author{
Ehsan Mirkamandar, ${ }^{1}$ Mohammad Reza \\ Shakibaie, ${ }^{2}$ Saeed Adeli, ${ }^{2}$ \\ Mitra Mehrabani, ${ }^{3}$ \\ Mohammad Mehdi Hayatbakhsh, ${ }^{4}$ \\ Saeed Esmailian \\ 'Student Research Committee, \\ 2Department of Microbiology and \\ Environmental health research center \\ ${ }^{3} \mathrm{Herbal}$ and Traditional Medicines \\ Research Center, Kerman University of \\ Medical Sciences, Kerman; \\ ${ }^{4}$ Gastroenterology Division, Department \\ of Internal Medicine, Afzalipoor Hospital, \\ Kerman, Iran
}

\section{Abstract}

The aim of this study was to evaluate the in vitro antimicrobial activity of a methanolic extract of Salvadora persica solution on Helicobacter pylori isolated from duodenal ulcer. Over 22 strains of $\mathrm{H}$. pylori were isolated from duodenal ulcer from August 2010 to June 2011. The $S$. persica stem was purchased from a local herb market and finely powdered. Extraction was performed with $60 \%$ methanol using a soxhlet extractor for $48 \mathrm{~h}$ until the solvent turned colorless while being incubated in an oven at $40^{\circ} \mathrm{C}$ for $48 \mathrm{~h}$ till dried. Dry powder was used to determine antimicrobial activity by the agar ditch method. Minimum inhibitory concentration (MIC) and minimal bactericidal concentration (MBC) of the extract were determined by the agar dilution method. At concentrations of $10,100,200,500 \mu \mathrm{g} / \mathrm{mL}$, no zone of inhibition around the ditches was observed while a clear zone of inhibition (12 $\mathrm{mm}$ ) was detected at $1000 \mu \mathrm{g} / \mathrm{mL}$ concentration for all the isolates. The best antimicrobial activity was observed at MIC $1000 \mu \mathrm{g} / \mathrm{mL}$ $(\mathrm{P} \leq 0.05)$. Furthermore, 10 out of 22 isolates were inhibited at $750 \mathrm{\mu g} / \mathrm{mL}$ of the extract. The $\mathrm{MBC}$ results showed that at a concentration of $1000 \mu \mathrm{g} / \mathrm{mL}$ all cells were dead while at a concentration of $750 \mu \mathrm{g} / \mathrm{mL}$ of $S$. persica a few $H$. pylori cells were still able to form colonies on Brucella agar supplemented with sheep red blood cells and antibiotics. From the above results it can be concluded that high concentration of S.persica could inhibit the growth of $\mathrm{H}$. pylori and MIC and MBC were similar at that concentration.

\section{Introduction}

Salvadora persica is a small tree or shrub with a crooked trunk, seldom more than one foot in diameter. Its bark is scabrous and cracked, whitish with pendulous extremities. The root bark of the tree is similar to sand and the inner surfaces are an even lighter shade of brown. It has a pleasant fragrance and a warm and pungent taste. Young branches are green in color with a slightly rough bark, grayishbrown on the main stem, paler elsewhere. Leaves are oblong-elliptic to almost circular measuring $3 \times 7 \mathrm{~cm}$, light to dark green in color. They are rather fleshy, sometimes with wartlike glandular dots and dense, rather loose hairs.It sheds its leaves from late December to January. The leaves break with a fine crisp crackle when they are trodden on. ${ }^{1}$

$S$. persica is a popular chewing stick (Miswak) throughout the Indian subcontinent, as well as the wider Muslim world. ${ }^{2,3}$ A chemical and phytochemical analysis of $S$. persica has identified carbohydrates and trimethylamine, an alkaloid which may effectively be salvadorine, chlorides, sulfur, terpenes, vitamin C glycosides, large amounts of fluoride and silica, small amounts of tannins, saponins, flavonoids and sterols. ${ }^{4}$

There has been little research into the antimicrobial activity of $S$. persica on different microorganisms..$^{3,5,6}$ The antimicrobial activity of $S$. persica solution (Miswak) as a root canal cleaner was studied by Al-Sabawi et al. ${ }^{7}$ The results of the in vitro antimicrobial effect of alcoholic extract of $S$. persica $(1 \%, 5 \%, 10 \%$, $15 \%$ and $20 \%$ ) against aerobic and anaerobic bacteria revealed that the best antimicrobial effect for $S$. persica extract was observed at $15 \%$ concentration according to a broth microdilution method. Antimicrobial activity of Miswak extract ( $S$. persica) in commercially available non-alcoholic mouth rinses was compared and it was found that $S$. persica has good activity against oral microflora. ${ }^{8}$ In one study in Pakistan, the antimicrobial effect of aqueous extract of seven different types of chewing sticks was compared. ${ }^{9}$ It was found that $S$. persica extract can inhibit the growth of Entrococcus fecalis at a concentration of 50\%.

Another study showed that Streptococcus mutans was more susceptible to Miswaks antimicrobial activity than Lactobacilli. ${ }^{10,11}$

The effect of mouth wash extracted from $S$. persica (Miswak) on dental plaque formation was investigated ${ }^{12}$ and it was found that crude $S$. persica extract solution was well tolerated by experimental animals. A disc diffusion test showed a marked antibacterial effect in vitro and this effect was concentration dependent. The extract had an in vivo effect but this was not considered absolute. ${ }^{13}$ Al-Otaibi et al.14
Correspondence: Mohammad Reza Shakibaie, Department of Microbiology and Environmental health research center, Kerman University of Medical Sciences, End of 22-Bahman BLVD, 76167-14111, Kerman, Iran.

Tel. +98.341.3221660.64 - Fax: +98.341.3221676.

E-mail: mr_shakibaei@kmu.ac.ir; mohammadreza.shakibaie@gmail.com

Key words: Helicobacter pylori, Salvadora persica extraction, minimum inhibitory concentration, minimal bactericidal concentration.

Acknowledgments: the authors would like to thank the research council of Kerman University of Medical Sciences for providing financial support for this project and the staff of the Department of Microbiology for their help during this research.

Received for publication: 12 October 2011. Revision received: 8 January 2012.

Accepted for publication: 8 February 2012.

This work is licensed under a Creative Commons Attribution NonCommercial 3.0 License (CC BYNC 3.0).

CCopyright E. Mirkamandar et al., 2012

Licensee PAGEPress, Italy

Microbiology Research 2012; 3:e9

doi:10.4081/mr.2012.es

studied the effect of chewing sticks and tooth brushing on plaque removal and gingival health. Similarly, Geetha et al. ${ }^{15}$ investigated the control of urinary risk factors of stone formation by $S$. persica in experimental hyperoxaluria.

H. pylori is a gram negative motile microaerophilic short rod bacterium that is responsible for most peptic ulcers and many cases of stomach inflammation (chronic gastritis). ${ }^{16}$

Those living in developing countries or in crowded, insanitary conditions are most likely to contract the bacterium which is passed from person to person. H. pylori only grows in the stomach and is usually the cause of more than half the peptic ulcers worldwide. ${ }^{17}$ The bacterium causes peptic ulcer by damaging the mucous coating that protects the stomach and duodenum. Damage to the mucous coating allows powerful stomach acid to get through to the sensitive lining beneath. Together, the stomach acid and $H$. pylori irritate the lining of the stomach or duodenum and cause an ulcer contracted during childhood. ${ }^{18}$

Each year a considerable amount of time and money is wasted on treating infection caused by $H$. pylori. The drugs on the market are generally tetracycline, claritomycine, metronidazole, a proton pump inhibitor, and bismuth subsilate. Drug resistant strains are to be found growing in different parts of the 
world and this makes therapy for infection caused by this bacterium more complicated. Furthermore, $H$. pylori treatment may cause side effects in some patients. Therefore, investigations into anti-H. pylori plant extracts with negligible side effects are very important.

There is a little information on the antimicrobial effect of $S$. persica on $H$. pylori. in vitro susceptibility of $H$. pylori to licorice extract showed that it inhibited $H$. pylori strains with a minimum inhibitory concentration (MIC) range of $50-400 \mathrm{mg} / \mathrm{mL} .^{19}$

Teymournejad et al. ${ }^{20}$ studied the effect of different concentrations of the $S$. persica extract on the $H$. pylori in the mouth (dental plaque). It was observed that at high concentrations of the plant extract the growth of bacteria was inhibited.

In this investigation, we evaluated the antimicrobial activity of $S$. persica extract on $H$. pylori strains isolated from duodenal ulcer biopsies of patients presenting with duodenal ulcer and vomiting at the Afzalipoor gastroenterology unit in Kerman, Iran.

\section{Materials and Methods}

\section{Specimen collection}

More than $22 \mathrm{H}$. pylori positive specimens were collected from patients of both sexes with abdominal discomfort, dyspepsia and poor appetite referred to the endoscopic section of the Gastroenterology Division of the Afzalipoor Hospital in Kerman, Iran, from August 2010 to June 2011. Some of them had bloody or black stools and vomiting. Three biopsies were taken from curvature of the antrum and duodenum (2-3 $\mathrm{cm}$ from pilor valve) of patients in the morning session between 8 to $12 \mathrm{am}$. All endoscopic examinations were performed with only local anesthesia.

One specimen was used for rapid urease test and two others were transferred into two tubes containing $500 \mu \mathrm{L}$ of sterile brain hearth infusion (BHI) broth and brought to the Department of Microbiology Laboratory for further analysis. There, $100 \mu \mathrm{L}$ of the specimens were inoculated into a sterile Brucella agar (Merck-Germany) plate containing 10\% sheep blood cells and antibiotics such as vancomycin, terimethoprime, and amphotericin-B added as supplements. The plates were incubated under microaerophilic conditions for three days at $37^{\circ} \mathrm{C}$ as described previously. ${ }^{21}$

\section{Bacterial identification}

The identification of $H$. pylori from specimens was carried out by biochemical tests, as well as morphology and gram staining. Colony characteristics on sheep blood agar, urease, oxidase, and catalase testes were also studied. ${ }^{22}$

\section{Plant material}

Dried stems of $S$. persica were purchased from a local medicinal herb market in Kerman,in the south east of Iran and identified by our pharmacognosist at the Herbal and Traditional Medicines Research Center, Kerman University of Medical Sciences.

\section{Extraction method}

Plant materials (stems) were cut by using a sharp knife and ground to a powder with a commercially available food blender. One hundred grams of the powdered stems (mesh 40) were extracted with $60 \%$ methanol (MerckGermany) using a soxhlet extractor for $48 \mathrm{~h}$ until the solvent turned colorless. The solvent was then removed from the extractor using a rotary vacuum evaporator at $40^{\circ} \mathrm{C}$ for four hours until a concentrated extract was obtained. The extract was incubated in an oven at $40^{\circ} \mathrm{C}$ until it yielded $8 \mathrm{~g}$ dry powder which was then stored in sterile screw capped vials in the refrigerator at $4^{\circ} \mathrm{C}$ until use..$^{13}$

\section{Antimicrobial activity}

The ditch plate method was used to study the antimicrobial activity of $S$. persica extract. Three to four colonies of the isolates were suspended in $3 \mathrm{~mL}$ of sterile distilled water, gently shaken and a lawn culture was spread on the sterile Brucella agar plate containing 10\% sheep blood and antibiotic supplements. Then $0.1 \mathrm{~mL}$ of different aliquots of the plant extract $(10,100,200,750,1000 \mu \mathrm{g} / \mathrm{mL})$ were pipetted Into the ditches made at the center of petri dishes. The plates were then incubated at $37^{\circ} \mathrm{C}$ for three days as described previously and examined for inhibition zones of the growth of the bacteria around the ditches. The average size of these zones was recorded in millimeters.

\section{Determination of minimum inhibitory concentration of extract by the agar dilution method}

In this method, 6 flasks containing $25 \mathrm{~mL}$ of Muller-Hinton agar were prepared and autoclaved at $120^{\circ} \mathrm{C}(15 \mathrm{LB})$ for $15 \mathrm{~min}$. We then added $10 \mathrm{~mL}$ sheep blood (Darvash Ltd., Iran) and different concentrations of $S$. persica plant extract $(10 \mu \mathrm{g} / \mathrm{mL}, 100 \mu \mathrm{g} / \mathrm{mL}, 200 \mu \mathrm{g} / \mathrm{mL}, 500$ $\mu \mathrm{g} / \mathrm{mL}, 750 \mu \mathrm{g} / \mathrm{mL}, 1000 \mu \mathrm{g} / \mathrm{mL}$ ) at $45^{\circ} \mathrm{C}$ and the preparation was allowed to solidify at room temperature. The bacterial suspensions were spot inoculated at a concentration of $1 \times 10^{7} \mathrm{CFU} / \mathrm{mL}$ onto each plate.

MIC was determined after three days of incubation at $37^{\circ} \mathrm{C}$ under microaerophilic conditions. MIC was defined as the lowest concen- trations of the extract that inhibited visible bacterial growth on the plates. At the same time, a negative control (inability to grow) containing Muller-Hinton agar plate and a positive control (able to grow) containing Brucella agar supplemented with $10 \%$ sheep blood were prepared and inoculated with the $H$. pylori isolates and incubated under microaerophilic conditions in the incubator at $37^{\circ} \mathrm{C}$.

\section{Determination of minimal bacterici- dal concentration of the extract}

Minimal bactericidal concentration (MBC) of the $S$. persica extract against $H$. pylori clinical isolates was measured by inoculating sterile swab from the MIC spot onto Brucella agar supplemented with $10 \%$ sheep red blood cells and antibiotics. After three days of incubation under microaerophilic conditions the growth (visible colonies) were checked.

\section{Statistical analysis}

All analyses were performed using SPSS, version 16.0 (SPSS Inc., Chicago, IL, USA). All $P$ values were two-tailed; $P \leq 0.05$ was considered statistically significant. Means and standard deviations (SD) were calculated as required for numerical variables.

\section{Results and Discussion}

From August 2010 to June 2011, more than $22 \mathrm{H}$. pylori were collected from patients undergoing endoscopic follow up for the early detection of gastric and duodenal ulcer at the Gastroenterology Division of the Afzalipoor Hospital in Kerman, Iran. Both male and female patients were included; average age $63 \pm 0.8$ years. Figure 1 shows the colony characteristics of $H$. pylori isolates on Brucella agar medium supplemented with $10 \%$ sheep blood and vancomycin, terimethoprime, and amphotericin-B antibiotics.

The inhibitory concentrations of $S$. persica methanolic extract against $H$. pylori isolates by the agar ditch method are presented in Table 1. As shown, at concentrations of 10, 100, 200, $500 \mu \mathrm{g} / \mathrm{mL}$ there was no zone of inhibition of the growth around the ditches while a clear zone of inhibition (12 mm) was observed at a concentration of $1000 \mu \mathrm{g} / \mathrm{mL}$ of the extract for all the isolates. Furthermore, $10 \mathrm{H}$. pylori isolates $(1,2,4,6,7,8,13,15,20$ and 21) showed a zone of inhibition $(8 \mathrm{~mm})$ at a concentration of $750 \mu \mathrm{g} / \mathrm{mL}$ concentration of the $S$. persica extract $(\mathrm{P} \leq 0.05)$. These results were further confirmed by MIC determination as shown in Table 2.

Our results clearly showed that $S$. persica extract exerted antimicrobial activity against H. pylori clinical isolates only at a high concen- 


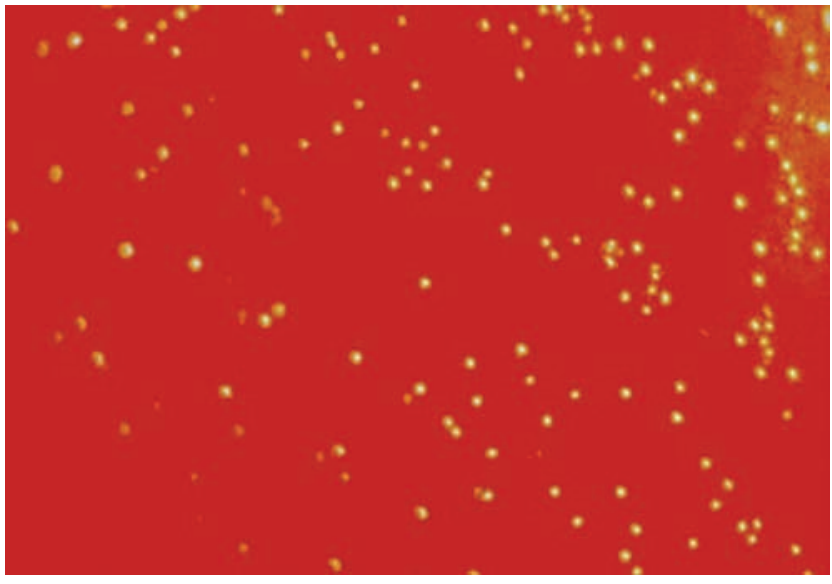

Figure 1. Colony characteristics of $H$. pylori on Brucella agar medium supplemented by $10 \%$ sheep blood and antibiotics.

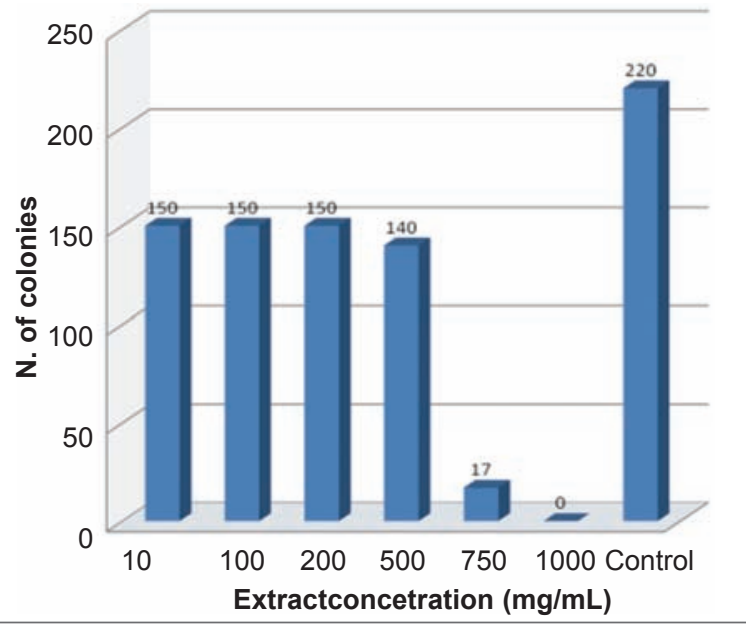

Figure 2. Minimum bactericidal concentration of $S$. persica extract on $\mathrm{H}$. pylori isolated from stomch ulcer.

Table 1. Antimicrobial activity of methanolic extract of $S$. persica against $H$. pylori isolates by agar ditch method.

\begin{tabular}{lccc}
$\begin{array}{l}\text { Antimicrobia } \\
\text { activity }\end{array}$ & $\begin{array}{l}\text { Zone } \\
\text { diameter }(\mathrm{mm})\end{array}$ & $\begin{array}{l}\text { Extract } \\
\text { concentration }(\mathrm{jg} / \mathrm{mL})\end{array}$ & $\begin{array}{l}\text { N. isolates } \\
\text { show zone } \\
\text { of inhibition (\%) }\end{array}$ \\
- & 0 & $\geq 500$ & 0 \\
+ & $7 \pm 0.8$ & 750 & 45.4 \\
\hline+ & 12 & 1000 & 100 \\
\hline
\end{tabular}

$\mathrm{P} \leq 0.05$ was considered as significant of association. The above results are mean of 2 independent experiments. Means and standard deviations (SD) were calculated as required for numerical variables. At the same time a negative control consists of $H$. pylori positive selective medium without extract and a positive control with the extract was run alongside the tests.

Table 2. Minimum inhibitory concentration of $S$.persica extract against $H$. pylori strains isolated from the Gastroenterology Division of the Afzalipoor Hospital in Kerman, Iran.

\begin{tabular}{cccccccc}
$\begin{array}{c}\text { N. of isolates } \\
(1 \mathrm{gg} / \mathrm{mL})\end{array}$ & \multicolumn{9}{c}{$\begin{array}{c}\text { Extract concentration } \\
(\mu \mathrm{Hg} / \mathrm{mL})\end{array}$} \\
12 & 10 & 100 & 200 & 500 & 750 & 1000 & 1000 \\
& + & + & + & + & + & - & \\
10 & + & + & + & + & - & - & 750 \\
\hline
\end{tabular}

+ growth of the isolates on that concentration; - absence of growth of the isolates on that concentration. MIC, minimum inhibitory concentration. The above results are average of 2 independent experiments.

tration $(1000 \mu \mathrm{g} / \mathrm{mL})$ and was ineffective at low concentrations.

The best antimicrobial effect for $S$. persica extract was observed at a concentration of $1000 \mu \mathrm{g} / \mathrm{mL}$. The difference between this and the other concentrations was highly significant $(\mathrm{P} \leq 0.05)$. Furthermore, 10 of $22 \mathrm{H}$. pylori isolates were inhibited at a concentration of $750 \mu \mathrm{g} / \mathrm{mL}$ of extract. MBC results showed no bacterium was alive at a concentration of 1000 $\mu \mathrm{g} / \mathrm{mL}$ and all cells were dead, while at a concentration of $750 \mu \mathrm{g} / \mathrm{mL} S$. persica there were still a few $H$. pylori cells able to form colonies to the same MIC value on Brucella agar supple- mented with sheep red blood cells and antibiotics (vancomycin, terimethoprime, and amphotericin-B, (Figure 2).

The potential antimicrobial activity of $S$. persica was studied by Al-Sabawi et al.7

Results revealed that $15 \%$ alcoholic extract of $S$. persica had significant antimicrobial effect. There was no significant difference in these results compared to sodium hypochlorite and chlorhexidine, while there was a significant difference compared to normal saline.

Similarly, the disc-diffusion method was used to determine the susceptibility of $3 \mathrm{H}$. pylori isolates to methanol extracts of 23
Iranian plants. ${ }^{22}$ All tests were performed in triplicate. Among them, the extracts of Punica granatum and Juglans regia had remarkable anti-H. pylori activity with a mean inhibition zone diameter of 39 and $16 \mathrm{~mm}$ at 100 $\mu$ gdisc-1, respectively. In view of the results obtained with P. granatum (pomegranate), the peel extracts of nine cultivars of pomegranate were further assayed against the clinical isolates of $H$. pylori. The results revealed that all Iranian pomegranate cultivars, except for Alake-Shirin, showed significant in vitro activity against the clinical isolates of $H$. pylori. Similarly, H. pylori were isolated from 10 clinical and environmental samples from water and biopsies in Tehran, Iran. ${ }^{20}$ At a 1/16 dilution of stock there was complete inhibition of $H$. pylori growth.

One study ${ }^{23}$ reported the inhibitory effects of hot water extract of cacao mass (cocoa extract) on the adhesion of $H$. pylori to gastric epithelial cells. The inhibition rate of cocoa extract was significantly higher than that obtained with the extract of oolong tea, black tea, green tea and coffee. It was also shown that cocoa extract had bactericidal effect on $H$. pylori at a final concentration of $3.5-10 \%$.

Antifungal activities of $S$. persica and Juglans riga on different Candida species were studied by Noumi et al. ${ }^{24}$ Methanol, ethylacetate and diluted acetone extracts of $S$. persica and $J$. riga were screened for in vitro activity against Candida and it was found that $S$. persica exerted more antifungal activity than $J$. riga.

Treatment of peptic ulcer caused by $H$. pylori with current antibiotics is cumbersome, time consuming and some of them, such as tetracycline or clarithromycin ${ }^{25}$ have considerable side effects. Therefore, a plant extract like $S$. persica can replace antibiotics in the treatment of $H$. pylori peptic ulcer. 


\section{Conclusions}

Overall, our study revealed that $S$. persica at a high concentration can exert antimicrobial activity against $H$. pylori isolated from duodenal ulcer. The results of preliminary tests by the ditch method were further confirmed by determination of MIC of the plant extract. Furthermore, the $\mathrm{MBC}$ results showed that at high concentration of $S$. persica no $H$. pylori isolates were capable of forming colonies on Brucella gar containing sheep red blood cells.

\section{References}

1. Khatak M, Khatak S, Siddqui SS, et al. Salvadora persica. Pharmacoghnosy Review 2010;4:209-14.

2. Iyenger ERR, Patolia JS, Chikara J. A useful plant for coastal saline soils. Wastelands News 1992;32:50-1.

3. Soliman A, Amin HE, Batwa M. Oral hygiene and periodontal status associated with the use of Miswak or toothbrush among Saudi adult population. Cairo Dental Journal 2007;23:159-66.

4. Almas K. The antimicrobial effects of seven different types of Asian chewing sticks. Odonto-Stomatologie Tropicale 2001;96:17-20.

5. Khalessi AM, Pack AR, Thomson WM, Tomkins GR. An in vitro study of the plaque control efficacy of Persica: A commercially available herbal mouthwash containing extracts of Salvadora Persica. Int Dent J 2004;54:279-83.

6. Almas K, Al-Zeid Z. The Immediate Antimicrobial Effect of a Toothbrush and Miswak on Cariogenic Bacteria: A Clinical Study. J Contemp Dent Prac 2004;5:1-9.

7. Al-sabawi NA, Alsheikh Abdal AK, Taba MY.
The antimicrobial activity of Salvadora persica solution as root canal irrigant (a comparative study). University of Sharjah. J Pure Appl Sci 2007;4:69-91.

8. Almas K, Skaug N, Ahmad I. "An in vitro antimicrobial comparison of Miswak extract with commercially available nonalcohol mouthrinses. Int $\mathrm{J}$ Dent Hyg 2005;3:18-24.

9. Akhtar MS, Ajmal M. Significance of chewing-sticks (Miswak) in oral hygiene from a pharmacological view-point. Journal Pakistan Medical Association 1981;31:8995.

10. Batwa M, Bergström J, Batwa S, Al-Otaibi MF. Significance of chewing sticks (Miswak) in oral hygiene from a pharmacological view-point. Saudi Dental Journal 2006;18:125-33.

11. Almas K. The effect of Salvadora persica extracts (Miswak) and chlorhexidine gluconate on human dentin: a SEM study. J Contemp Dent Pract 2002;3:27-35.

12. Al-Bayati FA, AI-Koubaisi AH, Abdul Wahid A, Ameen Abdulla M. Effect of mouth wash extracted from Salvadora persica (Miswak) on dental plaque formation: A clinical trail. Journal of Medicinal Plants Research 2010;4:1446-54.

13. Albayati FA, Suleiman KD. In vitro antimicrobial activity of Salvadora persica L. extracts against some isolated oral pathogens in Iraq. Turk J Bio 2008;132:5762.

14. Al-Otaibi M, Al-Harthy M, Soder B, et al. Comparative effect of chewing sticks and tooth brushing on plaque removal and gingival health. Oral Health Prev Dent 2003;1:301-7.

15. Geetha K, Manavalan R, Venkappayya D. Control of urinary risk factors of stone formation by Salvadora persica in experimental hyperoxaluria. Exp Clin Pharmacol 2010;32:623-9.

16. Naomi U, Shiro K, Soichiro Y, et al.
Helicobacter pylori infection and the development of gastric cancer. $\mathrm{N}$ Engl $\mathrm{J}$ Med 2001;345:784-9.

17. Polk DB, Peek RM. Helicobacter pylori: gastric cancer and beyond. Nat Rev Cancer 2010;10:403-14.

18. Atherton JC, Blaser MJ. Coadaptation of Helicobacter pylori and humans: ancient history, modern implications. J Clin Invest 2009;119:2475-87.

19. Jafarian M, Ghazvini K. In vitro Susceptibility of Helicobacter pylori to Licorice Extract. Iranian Journal of Pharmaceutical Research 2007;6:69-72.

20. Teymournejad 0, Sattari M, Mobarez M, Esmaeili D. Antibacterial Effects of Persica Mouth Wash on Helicobacter pylori Growth. J Glob Infect Dis 2010;2:197-8.

21. Sivam GP, Potter JD. Helicobacter pylori-in vitro susceptibility to garlic (Allium sativum) extract. Nutr Cancer 1997;27: 118-21.

22. Hajimahmoodi M, Shams-Ardakani M, Saniee P, et al. In vitro antibacterial activity of some Iranian medicinal plant extracts against Helicobacter pylori. Nat Prod Res 2011;25:1059-66.

23. Susumu S, Haruhiko T, Hiroyuki Y, et al. The effect of Cocoa extract on the growth, adhesion and colonization of Helicobacter pylori. Prog Med 1999;19:1207-13.

24. Noumi E, Snoussi M, Hajlaoui H, et al. Antifungal properties of Salvadora persica and Juglans regia L. extracts against oral Candida strains. Euro Clin Microbiol Infect 2010;29:81-8.

25. Monforte MT, Miceli N, Mondello MR, et al. Antiulcer activity of Salvadora persica on experimental ASA-Induced Ulcer in rat: ultrastructural modifications. Pharma Biol 2001;39:289-92. 